Review

\title{
Barriers to Tobacco Control in China: A Narrative Review
}

\author{
Wancong Leng ${ }^{1}(\mathbb{D})$ and Rui $\mathrm{Mu}^{2, *(\mathbb{D})}$ \\ 1 School of Policy Studies, Faculty of Social Sciences and Law, University of Bristol, Bristol BS8 1QU, UK; \\ jf19453@bristol.ac.uk \\ 2 Faculty of Humanities and Social Sciences, Dalian University of Technology, Dalian 116024, China \\ * Correspondence: ruimu@dlut.edu.cn
}

Received: 7 November 2020; Accepted: 15 December 2020; Published: 16 December 2020

\begin{abstract}
This research chooses the method of narrative literature review to analyze the barriers in implementing tobacco regulatory policies in China and explore the strategies that can overcome these challenges. China is the world's largest producer and consumer of tobacco products. Although the prevalence of cigarette smoking declined from $34.5 \%$ to $27.7 \%$ between 1984 and 2015, the reduction over the 30 years has been slow. Therefore, effective tobacco regulatory policies are necessary. However, as the tobacco industry is one of the major sources of government revenue and an indispensable part of the national economy, the implementation of tobacco regulatory policies faces many challenges. In terms of the institutional dimension, the ambiguous attitude of national institutions and tobacco companies' development strategies impede the enforcement of tobacco policies. In addition, the primary economic barrier to tobacco control is the unwillingness of the government to raise value-added tax on tobacco. Finally, the social customs of exchanging individual cigarettes and gifting packaged cigarettes among adults and juveniles in China hinder the implementation of tobacco regulatory policies. In this case, a combined strategy of top-down and bottom-up approaches can remove these barriers, such as using the authoritative power to control tobacco use and raising non-smokers' awareness of smoking risks and public education.
\end{abstract}

Keywords: China; cigarettes; government regulations; health behavior; implementation science; social activism; smoking; tobacco

\section{Introduction}

China is the world's largest producer and consumer of tobacco products. The Chinese tobacco industry consists of tobacco cultivation, tobacco manufacture, and tobacco trade systems [1]. In terms of tobacco cultivation, tobacco is cultivated in all provinces and municipalities except for Beijing, Shanghai, Tianjin, and Tibet. Some of the second- and third-tier cities, such as Yunnan and Guizhou, even rely on tobacco to develop their local economies [1]. In terms of tobacco manufacturing, the Chinese tobacco industry is state-owned, which means a monopoly over the production of tobacco has been established and controlled by the governments. Despite reducing its production from 3,250,000 to 2,200,000 metric tons between 2010 and 2019, China remains the world's largest tobacco producer [2]. The tobacco trade system mainly includes distribution points and point-of-sale subsystems. From 1996 to 2000, China invested about 4.2 billion yuan in the tobacco distribution system, and 16530 distribution points were established nationwide [3]. Yang et al. summarized the overall status of the smoking prevalence in China [4]. According to the first national tobacco use survey, conducted by the National Patriotic Health Campaign Committee in 1984, the average smoking rate among the Chinese population was $34.45 \%$. In 2002, according to the Behavioral Risk Factors Survey, the prevalence of smoking among the Chinese population was $31.4 \%$. In 2015, the smoking rate in China was $27.7 \%$ [5]. Although the 
smoking rate has been declining, the reduction over the past 20 years was not enough: it decreased by merely $6.75 \%$ [6]. Apart from active smoking, about $70 \%$ of adults are exposed to second-hand smoke (SHS) every week, and nearly 100,000 people die from SHS in China every year [7].

Scholars hold various views on the impacts of tobacco use in China. It is undeniable that, in terms of health, almost all scholars in this area have reached the consensus that smoking causes serious harm to physical health [8]. First of all, smoking causes many diseases. Case-control research in major Chinese cities has found a close correlation between lung cancer incidence and smoking. Smokers aged between 35 and 69 are about three times more likely to develop lung cancer than non-smokers [9]. In addition, smoking is one of the leading risk factors for premature death. In China, the death rate associated with smoking is remarkably high, and the number will continue to rise. By 2010, about 1 million people in China had died from smoking. It is estimated that this number will increase to 2 million by 2025 [10]. Most fatalities due to smoking are in persons below 65 years of age, thus preventing them from becoming old enough to suffer the very expensive illnesses of old age. Therefore, smoking restriction increases life expectancy from a long-term perspective. In terms of the economy, although the tobacco industry contributes half of the government's revenue, some scholars from China, such as $\mathrm{Hu}$ et al., indicate that smoking does bring negative effects to the national health, thus putting pressure on national medical care [11]. On the one hand, smoking leads to an increase in national investment in medical costs. According to a report from the National Health and Family Planning Commission, annual healthcare costs by smokers were $20 \%$ to $25 \%$ higher than healthcare costs for non-smokers since 2004 [12]. The increase of government investment in healthcare means the inevitable decrease in investment in other fields, such as education, which may lead to an imbalance in national development. On the other hand, smoking also affects the workers' productivity due to the health problem it causes. Tobacco-related health problems mainly affect the middle-aged population, which is the backbone of the workforce, thus posing an obstacle to overall economic growth [13].

There are many products on the Chinese tobacco market, some of which may be of value for tobacco harm reduction, such as e-cigarettes. As the products that reduce tobacco harm are beyond the scope of this research, this article focuses on three traditional anti-smoking interventions that are related to combustible cigarettes: smoke-free policies, tobacco taxes, and health warnings on tobacco products. Smoke-free policies in China can be divided into two dimensions: the national dimension and the urban dimension. Zhang et al. state that the Chinese government has taken many supportive measures to control tobacco use from the national dimension, such as the ban on smoking in all places related to children, announced by the Ministry of Health in 2007 [14]. In terms of the urban dimension, more than 12 cities in China have taken action to enact or amend legislation about the smoke-free environment. For instance, the capital city of Heilongjiang province has enacted regulations to protect people from passive smoking [15]. Some scholars assert that the most effective way to reduce tobacco use is to increase tobacco taxes [16]. However, the controversy about whether the increase of tobacco taxes will damage the national economic development has always existed. Jha et al. insist that raising tobacco taxes will not damage the government's profits and economic development [17]. In contrast, there are also people who argue that the smuggling activity would increase and emerge as a challenging issue to deal with if the taxes on cigarettes were to be raised. They also claim that it would affect the economy and make it hard to control the tar and nicotine content of cigarettes. Yang et al. argue that it is cost-effective for the government to impose health warning labels on tobacco products [18]. In October 2008, the health warning labels were placed in the main display area, covering $30 \%$ of the front and 30\% of the package's back. Warning messages have also been changed to "quit smoking to reduce health risks" and "quitting smoking early is good for health". However, Wan et al. state that the size and information of the tobacco packaging warning in China still need to improve to meet the requirements of the Framework Convention on Tobacco Control (FCTC) [19]. As the tobacco industry has emerged as an indispensable part of the national economy by contributing a great deal to the government's revenue, China will face many challenges in trying to implement the existing tobacco regulatory policies. 
The aims of this research are to (1) summarize the current governmental tobacco production and consumption policies, (2) identify and analyze the barriers to effective health-promoting policy changes, and (3) propose a comprehensive implementation strategy for tobacco-related reforms in China. Much of the literature on smoking restrictions in China discusses the current status of tobacco use and existing tobacco regulatory policies. Most scholars in this field have also concluded that the implementation of tobacco regulatory policies in China is not yet up to expectations. However, the difficulties in implementing these policies have gained little attention. Hence, this study summarizes what has been accomplished regarding tobacco control in China, without repetition, and analyzes the barriers to effective tobacco regulatory policies in China. In addition, the current research in this field fails to combine theory and reality. Many studies have mentioned the improvement of existing tobacco policies, but few scholars have analyzed strategies to overcome the policy deficiencies from the perspective of implementation theories. Therefore, this article analyzes the potential strategies by which we can overcome these difficulties in combination with the theories of policy implementation. Theoretically, the review of barriers to tobacco policy implementation provides new insights and lays the basis for future research.

\section{Materials and Methods}

There are three reasons why the literature-based method was chosen for this study. First of all, by the literature-based method, we can comprehensively and correctly grasp the research subject's status quo and make the best use of the existing knowledge, experience, and scientific research achievements to help researchers identify research topics [20]. Moreover, we can also use this method to build on ideas and make some innovation points in this research. Finally, scholars hold different views on tobacco control in China, and the literature-based method can evaluate the published articles and provide some of the best evidence available to us [21].

The literature-based approach involves a variety of methods. Narrative literature reviews (NRs) and systematic literature reviews (SRs) are the most widely used among them [22]. NRs have been applied in this research. Compared with SRs, NRs are more suitable for general debates and the evaluation of previous studies and insufficient knowledge at present [23]. Although there are many studies related to the pros and cons of tobacco policies in China, and most scholars agree that the implementation of these policies has not fully met the requirements or achieved the expected results, it is necessary to explore the barriers to implementing these policies. Through the NRs, we can summarize previous studies, avoid repetition, and observe the gaps. However, the most prominent weaknesses are the intense subjectivity in the selection of literature and the possible bias in the conclusions [24]. This research will review academic articles and search for governmental and non-governmental reports to minimize this disadvantage.

Four eligibility criteria are adopted in this article to identify relevant publications. In terms of the research field, all publications should be related to tobacco control in China. As regards the topic, the search terms are divided into two types. When searching for the literature on the implementation of tobacco policies in China, the key terms are "tobacco policy + barriers + China". When searching for the literature related to policy implementation theories, the key term is "theories of implementation". The specific search terms are listed in Table 1. In terms of the publication type, three types of literature are included in this research: (1) Academic articles-Peer-reviewed articles published in prestigious journals; (2) Government report-Reports published by the Ministry of health about tobacco policies in China; (3) Non-governmental reports-Reports from different non-governmental organizations which support tobacco control in China. Finally, as tobacco use is a long-standing problem in China, the published years of the literature are divided into two sections: 1999-2010 and 2010-2020. The year 1999 has been chosen as the beginning point because this year is a turning point in the development of Chinese tobacco policies. In 1999, tobacco control became part of the government's agenda. By reviewing the literature released in the past 20 years, the development and changes in tobacco regulatory policies over time can be clearly presented. 
Table 1. Search terms of literature.

\begin{tabular}{|c|c|c|c|c|}
\hline \multirow{2}{*}{$\begin{array}{c}\text { Category } \\
\text { tobacco policy } \\
\text { barriers } \\
\text { theories of } \\
\text { implementation }\end{array}$} & \multicolumn{4}{|c|}{ Keywords } \\
\hline & $\begin{array}{c}\text { smoke-free } \\
\text { political leadership } \\
\text { top-down }\end{array}$ & $\begin{array}{c}\text { tobacco taxes } \\
\text { national institutions } \\
\text { bottom-up }\end{array}$ & $\begin{array}{l}\text { health warning } \\
\text { tobacco companies }\end{array}$ & social customs \\
\hline
\end{tabular}

\section{Results and Discussion}

\subsection{Institutional Barriers to Effective Tobacco Regulatory Policy Implementation}

\subsubsection{Institutional Barriers at the National Institutional Level}

Any attempt to control tobacco production and consumption growth must consider the complexity of Chinese tobacco institutions [25]. The central node in the institutions is the State Tobacco Monopoly Administration (STMA). Hence, this section introduces the structure of the STMA and discusses the institutional barriers to the implementation of tobacco policies through the STMA's ambiguous attitude toward smoking restriction.

In 1984, the STMA was established. From 1984 to 2008, the STMA changed its bureaucracy several times, and finally, the newly established Ministry of Industry and Information Technology (MIIT) was put in charge [26]. To prevent tobacco-related official corruption, the Central Discipline Inspection Commission of the CCP (Chinese Communist Party) has set up an internal investigation team at the STMA [27]. A report from the World Health Organization states that the STMA is ambiguous about tobacco control as a government agency that oversees the national tobacco industry [28]. On the one hand, the STMA insists that tobacco is harmful to human health. On the other hand, it is concerned that tobacco control affects social stability because many people are dependent on tobacco cultivation and sale for their living [29]. There are two reasons for this contradictory attitude. The first reason is that the rapid growth of the tobacco industry makes the STMA control 40\% of the entire tobacco industry's profits in China. Thus, the STMA is not willing to place strict restrictions on tobacco production and sales [30]. Research from China points out that compared with other state-owned industries, tobacco interest groups have three unique advantages [31]. Firstly, the STMA, which oversees the tobacco industry, is the same body as the CNTC, regulating tobacco production and sale. Secondly, due to the fact that it benefits heavily from the lucrative business of the tobacco industry in its dual identity, the STMA is more likely to represent the tobacco industry's interests than any other large state-owned enterprise [32]. Thirdly, the STMA has a stable vertical network of branches, which helps to promote the development of the tobacco industry [33]. Another reason is that the STMA is trying to enhance the global competitiveness of the Chinese tobacco industry by increasing the production of cigarettes in China. Due to this reason, the Chinese tobacco industry needs to produce more cigarettes. Hence, the STMA decided not to issue production licenses to tobacco companies with an annual production capacity of less than 5 billion cigarettes to encourage the tobacco industry to increase its productivity [34]. This behavior runs counter to the requirement of reducing tobacco production through tobacco regulatory policies.

\subsubsection{Institutional Barriers at the Tobacco Company Level}

It is undeniable that the national institutions play a crucial role in implementing tobacco regulatory policies. However, due to the multi-level tobacco economy, subnational stakeholders such as tobacco companies cannot be ignored [35]. Tobacco companies and factories have been the most active participants in promoting tobacco development in China [36]. The Hongta Group, based in Yunnan province, is the largest Chinese cigarette maker and one of the world's largest tobacco companies, with a production of 93 billion cigarettes every year. In the Chinese tobacco industry, Hongta Group is often considered as "the banner of the national industry in China" [37]. Thus, in this section, the Hongta 
Group will be taken as an example to discuss how tobacco companies impede the implementation of tobacco regulatory policies.

A study from China demonstrates that the Hongta Group's obstacles to tobacco policies' implementation are mainly reflected in its development strategy [38]. First, the Hongta Group "persuaded" the Yunnan provincial government to introduce policies that would benefit the development of tobacco companies. In 1988, a large earthquake struck Yunnan Province. After the event, the Hongta Group lobbied the provincial government to introduce a policy of "expanding tobacco production to alleviate the damage caused by the earthquake" [39]. In this case, the government's measure to expand tobacco production was due to the fact that it needed to raise more funds. In addition, the Hongta Group has taken various measures to expand its domestic market. Since 1994, the Hongta Group has set up about 12,000 tobacco stores all over the country [40]. Later, the Hongta Group has established stores selling Hongta brand cigarettes in airports in six major cities, including Shenzhen, Shanghai, etc. Finally, the Hongta Group has adopted the strategy of mergers and acquisitions. It merged with Changchun tobacco factory and acquired Liaoning tobacco company, in Shenyang, and Hainan tobacco company, in Sanya [41]. These mergers and acquisitions have led to a rapid growth in tobacco production in the Hongta Group, which is not conducive to the implementation of tobacco regulatory policies.

\subsection{Economic Barriers to Effective Tobacco Regulatory Policy Implementation}

The economic barriers to implementing tobacco regulatory policies are mainly reflected in tobacco taxes. Increasing tobacco taxes is one of the most effective ways to reduce tobacco use [42]. However, there has been a debate between academics and government institutions over whether to raise tobacco taxes in the context of controlling tobacco. Although an academic study from China has shown that increasing tobacco taxes does not reduce government revenues [43], government institutions such as the STMA are concerned that a decline in tobacco consumption will diminish the contribution of the tobacco industry to the national economy. To enforce tobacco policies more effectively, it is necessary to change the government's unwillingness to increase the value-added tobacco tax. The government's attitude toward the tobacco tax is influences by three main factors: government revenues, inflation, and employment. Therefore, this section briefly introduces the structure of tobacco taxes in China and discusses the relationship between tobacco taxes and these three factors.

\subsubsection{The Structure of Tobacco-Related Taxes in China}

China has three kinds of tobacco taxes. The first one is the tobacco leaf tax. Before 2005, the tobacco leaf tax fell under the agricultural tax. In 2006, it was redesigned as a special tobacco tax, and the tax rate was reduced from $31 \%$ to $20 \%$ [44]. The central government points out that the tobacco leaf tax is a macro-adjusting measure to control tobacco production and consumption and can be taken as an effective tobacco regulatory policy. Besides, it is a major source of revenue for the local governments. The second one is the value-added tax (VAT). A report from the World Health Organization indicates that a 17\% VAT was imposed on cigarette production in 1994 [45]. The imposition of VAT can raise the price of tobacco products, thus reducing tobacco consumption and achieving the goal of smoking restriction. In 2001, the cigarette excise tax was divided into two parts: one is the specific excise tax, the other is an ad valorem tax. The specific excise tax of all cigarettes is RMB 150 per box. An ad valorem tax of $45 \%$ is levied on cigarettes with a production price of 50 yuan or more, and of $30 \%$ on cigarettes with a value of less than 50 yuan [46].

\subsubsection{Tobacco Taxes and Government Revenue}

The tobacco taxes are important and reliable sources of revenue for the central government. For example, in 1997, China collected 90 billion yuan of tobacco taxes, accounting for about $11 \%$ of the central government's revenue [47]. Other factors also contribute to amplifying the importance of tobacco taxes. First of all, in some agricultural provinces in China, such as Yunnan province, the tax 
levied by the local governments on tobacco leaves is the primary source of its revenue. The local governments receive revenue mainly from two tobacco taxes: a $100 \%$ tobacco leaf tax and a $25 \%$ value-added tax [43]. In addition, the central and local governments share cigarette taxes from product taxes. The central government gives incentives to the local governments to promote cigarette production by giving them a $25 \%$ share of the VAT on cigarette products. The revenue-sharing scheme prompts the local governments to protect their interests in cigarette production, which leads to a local monopoly of tobacco production, in violation of the overall national goal of tobacco production [44]. Finally, the CNTC, a state-owned enterprise, provides the central government with a large amount of value-added taxes. As a result, higher tobacco taxes lead to reduced demand for cigarettes, and the measure that the central and local governments have taken would actually damage their revenues. However, research from India demonstrates that raising tobacco taxes will not damage the Chinese government's revenue and economic development [15]. By imposing an extra $10 \%$ tax on each cigarette pack, the Chinese government would raise more than twice as much as the total lost revenue from the industry, tobacco farmers, and local taxes [48].

\subsubsection{Tobacco Taxes and Inflation}

Consumer price indices reflect the average prices paid by typical consumers in a country. The growth percentage in consumer price indices measured the inflation rate which directly affects the domestic interest rate and foreign exchange rate [46]. The government's unwillingness to raise tobacco taxes is due to its concerned that it will lead to inflation, especially in countries where wages are pegged to inflation or government policies require low inflation. Linegar and Walbeek (2018) explain that the impact of an increase in tobacco taxes on inflation depends on the percentage increase in tobacco prices and the weight given to tobacco prices when calculating the price index [47]. For instance, if the taxes account for $50 \%$ of a tobacco product's price, a $100 \%$ tax increase would raise the price by $50 \%$. If the weight of tobacco products in the price index is $3 \%$, the index will rise by $1.5 \%$ [33]. The percentage of tobacco expenditure in the total population can be used to estimate the impact of tobacco expenditure on the consumer price index. In fact, cigarettes account for only slightly more than $1 \%$ of all household expenditure In China [48]. Therefore, tobacco may play a small role in the price index. Besides, since the weight used to calculate price indices changes little and the consumption of products decreases due to tax increases, the impact of tobacco taxes' increase on inflation might be exaggerated [15].

\subsubsection{Tobacco Taxes and Employment}

Apart from revenues and inflation, employment is the third factor for the government's reluctance to raise tobacco taxes. An argument against raising tobacco taxes is that higher taxes would lead to fewer jobs and even a weaker economy [49]. The government argues that reductions in tobacco consumption would result in job losses in the tobacco industry. However, this is just one part of the picture. The number of tobacco-related jobs is overestimated because many are part-time and seasonal [44]. Due to the changes in prices, resources are constantly transferred between industries in a dynamic economy. Therefore, it is important to consider the relationship between tobacco taxes and net employment. As tobacco taxes increase, tobacco consumption decreases, and resources are transferred to other industries [50]. When consumers spend less on tobacco, they spend more on other goods, which directly creates more employment opportunities in other fields. The additional revenue generated by raising tobacco taxes does not disappear from the economy but is redirected by the government to other uses, creating jobs and profits in these areas [51]. In general, the loss in the tobacco sector is offset by a reallocation that generates alternative business opportunities in other sectors of the economy, as well as the jobs and income associated with them. Therefore, based on the existing evidence, it does seem that an increase in tobacco taxes will bring negative effects on employment in the country. 


\subsection{Social Barriers to the Effective Implementation of Tobacco Regulatory Policies}

Social custom is one of the most significant barriers to implementing tobacco regulatory policies [51]. Smoking has already been accepted by the public as a part of the customs of Chinese society. Since China has no formal laws limiting the minimum age for tobacco consumption, giving gifts and sharing cigarettes is common not only among adults but also among juveniles [52]. Individual cigarettes are generally exchanged in daily life, while whole packages or cartons of cigarettes are mainly given as gifts on holidays and special occasions [53]. Efforts to regulate tobacco use require an in-depth understanding of these social practices and customs. This section discusses the social barriers from two perspectives: cigarette sharing and cigarette gifting.

\subsubsection{Cigarette Sharing}

The prevalence of cigarette sharing in China can heavily affect the public attitude toward smoking and tobacco control. In different social contexts, the custom of sharing individual cigarettes is quite popular among members of different economic classes, including doctors, businessmen, and workers [54]. The most common motive for sharing cigarettes among different groups is to show courtesy. Men sharing cigarettes is usually related to masculinity. When two or more people gather together, regardless of whether they are meeting for the first time or have met before, they offer to share cigarettes with each other. If the second round of smoking is initiated, the responsibility for providing cigarettes is rotated among the group members to ensure an equal sharing [55]. This routine can be repeated many times, lasting several hours, and it not only promotes an active social interaction between men but also contributes to the consumption of a variety of cigarettes. To confirm the social status assigned by a particular brand, the price of cigarettes varies greatly [56]. Cigarettes given to a boss or business partner can be more expensive than those given to a neighbor or a doorman. In addition, sharing individual cigarettes is repeatedly described as a way to express the intimate relationship between giver and recipient [57]. Developing and maintaining such a relationship is actually beneficial to them in this competitive society. Smokers have adapted to this custom because refusing to share cigarettes can be interpreted as disrespectful. Ma et al. explain that refusing to accept cigarettes can be considered very rude behavior and may even lead to social exclusion [58]. In terms of gender, according to the World Health Organization, $57 \%$ of adult men smoke, but only $3 \%$ of adult women do. The widely held social norms exempted or even discouraged women from participating in exchanging personal cigarettes, so the tobacco exchange in China was limited to men [52]. However, as China continues to develop, these social norms that discourage women from smoking are likely to fade away, exposing more women to the social pressure of smoking. Hence, controlling the sharing of cigarettes is essential not only to reduce the smoking rate among men but also to prevent a potential increase in smoking among women.

\subsubsection{Cigarette Gifting}

Apart from the random gift, it is also common to give cigarettes as formal gifts in China. This social custom has increased the production of tobacco and seriously hindered the implementation of tobacco regulatory policies. To understand how deeply rooted the custom of cigarette gifting is in Chinese society, it is necessary to have a broad understanding of Chinese culture, customs, and ideologies, which can be traced back to the mainstream values in China-Confucianism [59]. Confucianism emphasizes the use of etiquette as the key to maintaining a harmonious social hierarchy. The clearest measure of whether a person's behavior is in line with the proper etiquette and social status is the gift [60]. In Chinese culture, this ritualized way of giving gifts has been incorporated into cigarettes. Acceptance of cigarettes can represent a person's willingness to engage in future business partnerships, legal or otherwise [61]. Individuals can excuse themselves from accepting cigarettes in public places where smoking prohibition is imposed. However, in reality, they just want to avoid establishing business relationships with the cigarette carriers. 
During the Mid-Autumn Festival and the Lunar New Year, complimentary packaged cigarettes are most common. People give expensive cigarettes to their families as gifts to show respect for the recipients and show the givers' financial success [62]. Ironically, a son or daughter who urges their parents to quit smoking is actually giving them expensive cigarettes as gifts. Chinese research points out that the reason behind this phenomenon is a misconception that more expensive cigarettes are inherently healthier, and therefore seem to be a more appropriate gift. There are three main reasons why people like giving cigarettes as gifts. Firstly, cigarettes are easy to carry, easy to buy, and non-perishable, and the price is well known among gift-givers and recipients [63]. Additionally, gifts with unequal values can lead to tension and disrespect on both sides. By giving cigarettes as a gift, the giver can make sure that the receiver will not misjudge the value of the gift. Finally, even for non-smokers, cigarettes are a suitable gift as well because they can transfer the cigarettes to their smoking friends and family members, thus saving them from buying gifts for others. Giving away expensive cigarettes is a heavy burden for lower-income Chinese families, that tend to be more focused on identity-oriented consumption. For these families, spending on cigarettes for personal use and gifts reduces spending on food, utilities, and education, which adversely affects other family members [64].

\subsection{Potential Strategies to Remove Barriers}

In China, many stakeholders are involved in the effort to implement smoking restrictions, such as the top political leaders, the national institutions, tobacco companies, etc. Hence, the promotion of tobacco control requires efforts from two dimensions: the top and the bottom. This section proposes a combined strategy of top-down and bottom-up implementation approaches to remove the barriers to effective tobacco control.

\subsubsection{Top-Down Implementation Approach}

Under the Communist Party of China (CPC)-led multi-party cooperation and political consultation system [65], the National People's Congress (NPC) is responsible for enacting laws. The Prime Minister is the head of government, directly headed by the President, who is the head of the state and the chairman of the political party [64]. This top-down management system is well designed. Once a senior official decides to enforce a policy initiative, the country can have a well-structured administration. Thus, the crucial success factor for smoking restriction in China is the top-level authority and appropriate leadership. It should be noted that the department responsible for tobacco production and sales should not be associated with the department in charge of tobacco control. The slow progress of tobacco control in China is mainly related to some government institutions, such as the STMA. Thus, ideally, a new National Tobacco Control Agency should be created directly under the State Council to coordinate tobacco regulatory actions.

By reviewing the existing evidence about the impact of tobacco taxes, the advocates of tobacco control should persuade the top leadership to adjust the existing tobacco policy. According to the Chinese existing tobacco tax system, improving the specific excise tax is the most convenient choice [41]. The specific excise tax is easy to collect, as is monitoring fake cigarette smuggling [65]. The current specific excise tax is low, only RMB 0.06 per pack. In order to control smoking more effectively, the specific excise tax should be increased to RMB 1 per pack. Apart from the specific excise tax, the Chinese government should also consider removing the tobacco tax revenue sharing between the central and local government, since local government sometimes subsidizes economically inefficient factories to produce excess tobacco leaf and cigarettes [42]. Replacing revenue sharing with the existing central government revenue transfer mechanism between the local governments and the central government can support local fiscal needs. The top-down approach emphasizes formal guidance on the issues and factors that are easy to manipulate, leading to centralization and control. However, some scholars have questioned this approach. Berman (1978) concludes that the top-down approach often ignores the diversity of the participants and policies with multiple objectives, and policy makers cannot control the process of policy implementation [66]. Hence, only the participation of top political 
leadership and lower-level actors in the enforcement of tobacco regulatory policies is efficient to overcome the barriers.

\subsubsection{Bottom-Up Implementation Approach}

In addition to top-level leadership, a bottom-up approach is also needed to promote the implementation of tobacco regulatory policies. The public would embrace this approach because they can participate in tobacco control. Momentum for change at the bottom level will give top leaders an incentive to control tobacco. Although there are 300 million smokers in China, the number of non-smokers is still larger than that of smokers [5]. Progress in tobacco control can only be accelerated when non-smokers realize that second-hand smoke is harmful to their health and that they deserve a smoke-free environment. With the widespread use of internet technology, social media and mainstream media can be used to increase people's awareness of the risks of smoking [66].

Partnerships among civil society and non-government organizations, opinion leaders, and other advocates can be an activator for the change in tobacco control. As part of the mission, other non-government organizations such as the Chinese Red Cross and the All-China Women's Federation as well as academic institutions such as the Chinese Preventive Medicine Association have begun to organize public education activities on the risks of tobacco in recent years [5]. Meanwhile, international organizations such as the World Health Organization, the American Cancer Society, and the Red Cross are also supporting tobacco regulatory programs in China by providing enough funds [67].

The pro-smoking culture in China can best be challenged by public education. Tobacco control advocates should work closely with the Publicity Department of the Chinese Communist Party, the Ministry of Education, the State Administration of Radio, Film and Television, and other governmental and non-governmental organizations to educate the public about the health risks of smoking [23]. Public education should first be targeted at doctors and other medical professionals as well as medical schools.

\subsection{Goals, Strengths, and Limitations}

The goal of this paper is to encourage governmental and non-governmental agencies to take the steps needed to enhance the efficacy of tobacco control in China. In support of this goal, this paper did not limit its review to published literature. It also reviewed a wide range of unpublished reports from Chinese governmental and non-governmental agencies. It did not review literature or reports from other countries, thus limiting the generalization of findings to China, and possibly depriving us of wisdom that might have been secured from other countries.

This study analyzes the barriers to the implementation of tobacco regulatory policies in China and discusses the strategies to overcome these barriers using a combination of top-down and bottom-up approaches. Future studies can use the comparative study to compare the implementation of tobacco regulatory policies in China and European countries. Future research should entail interviews with governmental and tobacco company staff to better understand their approach to tobacco-related policies. Moreover, future research can sort out and analyze the tobacco policies on government websites to observe the development trend of policies from 2000 to 2020. Finally, the combination of a 32\% reduction in cigarette production between 2010 and 2019 and a $6.75 \%$ reduction in smoking prevalence from 1984 to 2015 indicates that the possible presence of a huge black market for cigarettes has existed in China. This topic is worthy of study and government action.

\section{Conclusions}

This paper summarizes current governmental and tobacco company smoking and anti-smoking policies and barriers to more effective tobacco control policies and programming in China. It proposes a set of "top-down' and "bottom-up" strategies to enhance the efficacy of tobacco control programming in China. Ambiguous attitudes and unwillingness to limit the production of cigarettes are major barriers to effective tobacco control. The economic obstacles are mainly reflected in raising tobacco 
taxes. There are three reasons for the government's reluctance to take this step. First, the government is concerned that higher taxes on tobacco will result in a decrease in its revenue. Secondly, the government insists that the tobacco tax increase would lead to inflation. Thirdly, the government declares that raising tobacco taxes would reduce employment opportunities. The social custom of cigarette sharing in China is another prominent barrier to effective tobacco control. In daily life, people exchange individual cigarettes, and cigarettes are given as gifts on holidays and special occasions. By practicing the comprehensive strategy of top-down and bottom-up approaches, we can overcome the barriers above. From a top-down perspective, the one-party system in China is efficient in carrying out measures for smoking restriction. Meanwhile, a national tobacco regulatory agency should be set up directly under the State Council to coordinate tobacco regulatory actions. From a bottom-up perspective, increasing the risk awareness of non-smokers and public education can effectively promote tobacco control.

Author Contributions: Conceptualization, W.L.; methodology, W.L.; validation, W.L. and R.M.; resources, W.L.; writing-original draft preparation, W.L.; writing—review and editing, R.M.; visualization, W.L. All authors have read and agreed to the published version of the manuscript.

Funding: The APC is paid by Talent Program of Xinghai Scholar at Dalian University of Technology (grant number: 2400-82213004), and Liaoning Revitalization Talents Program (grant number: XLYC1807057).

Conflicts of Interest: The authors declare no conflict of interest.

\section{References}

1. Wang, W. The WTO and FCTC dispute settlement systems: Friends or foes? SSRN Electron. J. 2005, 6, 168-175.

2. Shahbandeh, M. World Tobacco Production by Country. 2020. Available online: https://www.statista.com/ statistics/261173/leading-countries-in-tobacco-production (accessed on 18 September 2020).

3. Lin, H.; Chang, C.; Liu, Z.; Zheng, Y. Subnational smoke-free laws in China. Tob. Induc. Dis. 2019, 17, 78. [CrossRef]

4. Gan, Q.; Yang, J.; Yang, G.; Goniewicz, M.; Benowitz, N.; Glantz, S. Chinese "herbal” cigarettes are as carcinogenic and addictive as regular cigarettes. Cancer Epidemiol. Biomark. Prev. 2009, 18, 3497-3501. [CrossRef]

5. Parascandola, M.; Xiao, L. Tobacco and the lung cancer epidemic in China. Transl. Lung Cancer Res. 2019, 8, S21-S30. [CrossRef]

6. Hu, T. China at the crossroads: The economics of tobacco and health. Tob. Control 2006, 15, 37-41. [CrossRef] [PubMed]

7. Madewell, Z. The belief that second-hand smoke causes serious illness among Chinese smokers: Smoking cessation and intention to quit. Tob. Prev. Cessat. 2018, 4, 35-42. [CrossRef] [PubMed]

8. Gan, Q.; Smith, K.; Hammond, S.; Hu, T. Disease burden of adult lung cancer and ischemic heart disease from passive tobacco smoking in China. Tob. Control 2007, 16, 417-422. [CrossRef]

9. Peto, R. Mortality from Smoking in Developed Countries 1950-2000; Oxford University Press: Oxford, UK, 2003.

10. Ma, S.; Hoang, M.; Samet, J.; Wang, J.; Mei, C.; Xu, X.; Stillman, F. Myths and attitudes that sustain smoking in China. J. Health Commun. 2008, 13, 54-66. [CrossRef] [PubMed]

11. Hu, X.; Fan, W. Ultra-Flexible polarization-insensitive multiband terahertz metamaterial absorber. Appl. Opt. 2013, 54, 2376-2382.

12. Zhang, J.; Ou, J.; Bai, C. Tobacco smoking in China: Prevalence, disease burden, challenges and future strategies. Respirology 2011, 16, 1165-1172. [CrossRef] [PubMed]

13. Stillman, F.; Kaufman, M.; Zhen, A.; Yang, J.; Wang, J.; Zhao, N. Smoke-Free or not: A pilot evaluation in selected Beijing Hospitals. BMC Public Health 2013, 13, 964. [CrossRef] [PubMed]

14. Chaloupka, F.; Cummings, K.; Morley, C.; Horan, J. Tax, price and cigarette smoking: Evidence from the tobacco documents and implications for tobacco company marketing strategies. Tob. Control 2002, 11, 62-72. [CrossRef] [PubMed]

15. Verguet, S.; Gauvreau, C.; Mishra, S.; MacLennan, M.; Murphy, S.; Brouwer, E.; Nugent, R.; Zhao, K.; Jha, P.; Jamison, D. The consequences of tobacco tax on household health and finances in rich and poor smokers in China: An extended cost-effectiveness analysis. Lancet Glob. Health 2015, 3, 206-216. [CrossRef] 
16. Yang, G.; Wang, Y.; Wu, Y.; Yang, J.; Wan, X. The road to effective tobacco control in China. Lancet 2015, 385, 1019-1028. [CrossRef]

17. Wan, X.; Ma, S.; Hoek, J.; Yang, J.; Wu, L.; Zhou, J.; Yang, G. Conflict of interest and FCTC implementation in China. Tob. Control 2012, 21, 412-415. [CrossRef]

18. Elmore, R. Backward mapping: Implementation research and policy decisions. Political Sci. Q. 1979, 94, 601. [CrossRef]

19. Chan, S.; Sarna, L.; Wong, D.; Lam, T. Nurses' tobacco-related knowledge, attitudes, and practice in four major cities in China. J. Nurs. Scholarsh. 2007, 39, 46-53. [CrossRef]

20. Cronin, P.; Ryan, F.; Coughlan, M. Undertaking a literature review: A step-by-step approach. Br. J. Nurs. 2008, 17, 38-43. [CrossRef]

21. Fichtenberg, C. Effect of smoke-free workplaces on smoking behavior: Systematic review. BMJ 2002, 325, 188. [CrossRef]

22. Benedictine University. Research Guides: Evaluating Sources: The CRAAP Test. 2019. Available online: https://researchguides.ben.edu/c.php?g=261612\&p=2441794 (accessed on 23 August 2020).

23. Li, C. The Political Mapping of China's Tobacco Industry and Anti-Smoking Campaign. 2012. Available online: https://www.brookings.edu/research/the-political-mapping-of-chinas-tobacco-industry-and-antismoking-campaign-2/ (accessed on 7 September 2020).

24. Shirk, S. China in Xi's "New Era". J. Democr. 2018, 29, 20-21.

25. Ho, M.; Ma, S.; Chai, W.; Xia, W.; Yang, G.; Novotny, T. Smoking among rural and urban young women in China. Tob. Control 2010, 19, 13-18. [CrossRef] [PubMed]

26. He, P.; Takeuchi, T.; Yano, E. An overview of the China National Tobacco Corporation and State Tobacco Monopoly Administration. Environ. Health Prev. Med. 2013, 18, 85-90. [CrossRef]

27. Chu, A.; Jiang, N.; Glantz, S. Transnational tobacco industry promotion of the cigarette gifting custom in China. Tob. Control 2011, 20, e3. [CrossRef] [PubMed]

28. Ho, L.; Schafferer, C.; Lee, J.; Yeh, C.; Hsieh, C. Raising cigarette excise tax to reduce consumption in low-and middle-income countries of the Asia-Pacific region: A simulation of the anticipated health and taxation revenues impacts. BMC Public Health 2018, 18, 1187. [CrossRef]

29. World Health Organization. Tobacco or health: A global status report. Geneva 2003, 18, 195.

30. Gambescia, S. Tobacco control policy: Strategies, success, \& setbacks. Tob. Control 2003, 12, 435.

31. Mackay, J. China: The tipping point in tobacco control. Br. Med Bull. 2016, 120, 15-25. [CrossRef]

32. Liao, A. China's STMA and the Tobacco Monopoly. 2015. Available online: https://www.tobaccoasia.com/ features/china\%E2\%80\%99s-stma-and-the-tobacco-monopoly/ (accessed on 8 September 2020).

33. Kohrman, M.; Quan, G.; Wennan, L.; Proctor, R. Poisonous Pandas; Stanford University Press: Stanford, CA, USA, 2018.

34. Lee, K.; Eckhardt, J.; Holden, C. Tobacco industry globalization and global health governance: Towards an interdisciplinary research agenda. Palgrave Commun. 2016, 2, 16037. [CrossRef]

35. Jiang, Y. Urgent need to ratify national legislation banning smoking in public places. China CDC Wkly. 2020, 2, 426-427. [CrossRef]

36. World Health Organization. WHO Launches New Report on Global Tobacco Use Trends? 2019. Available online: https://www.who.int/news-room/detail/19-12-2019-who-launches-new-report-on-global-tobaccouse-trends (accessed on 11 September 2020).

37. Saetern, H. Facts and myths about research on public policy implementation: Out-of-Fashion, allegedly dead, but still very much alive and relevant. Policy Stud. J. 2005, 33, 559-582. [CrossRef]

38. Smith, D.; Wei, N.; Zhang, Y.; Wang, R. Tobacco smoking habits among a cross-section of rural physicians in China. Aust. J. Rural Health 2006, 14, 66-71. [CrossRef] [PubMed]

39. Wakefield, M.; Loken, B.; Hornik, R. Use of mass media campaigns to change health behavior. Lancet 2014, $376,61-71$

40. Yao, T.; Sung, H.; Mao, Z.; Hu, T.; Max, W. The healthcare costs of second-hand smoke exposure in rural China. Tob. Control 2014, 24, 221-226. [CrossRef] [PubMed]

41. Xinhua Net. China Tobacco Control as the Negative Example. 2008. Available online: http://news.xinhuanet. com/herald/2008-11/27/content_10419853.htm (accessed on 12 September 2020).

42. World Health Organization. Smoke-Free policies in China: Evidence of effectiveness and implications for action. Geneva 2015, 19, 10-12. 
43. Briefing, C. Import-Export Taxes and Duties in China-China Briefing News. 2020. Available online: https: //www.china-briefing.com/news/import-export-taxes-and-duties-in-china/ (accessed on 12 September 2020).

44. Ekpu, V.; Brown, A. The economic impact of smoking and of reducing smoking prevalence: Review of evidence. Tob. Use Insights 2015, 8, 28. [CrossRef]

45. Van Walbeek, C. Measuring changes in the illicit cigarette market using government revenue data: The example of South Africa. Tob. Control 2013, 23, 69-74. [CrossRef]

46. Canadian Cancer Society. Tobacco Free Kids. 2018. Available online: https://www.tobaccofreekids.org/assets/ global/pdfs/en/WL_status_report_en.pdf (accessed on 9 August 2020).

47. Linegar, D.; van Walbeek, C. The effect of excise tax increases on cigarette prices in South Africa. Tob. Control 2018, 27, 65-71. [CrossRef]

48. Djibuti, M.; Gotsadze, G.; Mataradze, G.; Zoidze, A. Influence of household demographic and socio-economic factors on household expenditure on tobacco in six New Independent States. BMC Public Health 2017, 7, 222. [CrossRef]

49. Alchin, T. A note on tobacco product prices in the Australian CPI. Appl. Econ. Lett. 1995, 2, $473-477$. [CrossRef]

50. Koty, A. Up in Smoke: Why China Has Banned Foreign Investment in The Tobacco Industry-China Briefing News. 2016. Available online: https://www.china-briefing.com/news/why-china-has-bannedforeign-investment-in-the-tobacco-industry/ (accessed on 10 September 2020).

51. China Youth Daily. Collusion between Officials and Businessmen Undermines Implementation of China's Labour Law, Scholar Says. 2006. Available online: https://lb.org.hk/content/collusion-between-officialsand-businessmen-undermines-implementation-chinas-labour-law (accessed on 8 September 2020).

52. Kohrman, M. Depoliticizing tobacco's exceptionality: Male sociality, death and memory-making among chinese cigarette smokers. China J. 2007, 58, 85-109. [CrossRef]

53. Proctor, R. Why ban the sale of cigarettes? The case for abolition. Tob. Control 2012, 22, 27-30. [CrossRef] [PubMed]

54. Dong, G.; Cao, Y.; Ding, H.; Ma, Y.; Jin, J.; Zhao, Y.; He, Q. Effects of environmental tobacco smoke on respiratory health of boys and girls from kindergarten: Results from 15 districts of northern China. Indoor Air 2007, 17, 475-483. [CrossRef] [PubMed]

55. Centers for Disease Control and Prevention. Cigarette and Tobacco Use among People of Low Socioeconomic Status. 2019. Available online: https://www.cdc.gov/tobacco/disparities/low-ses/index.htm (accessed on 18 September 2020).

56. Li, J.; White, J.; Hu, T.; Fong, G.; Yuan, J. The heterogeneous effects of cigarette prices on brand choice in China: Implications for tobacco control policy. Tob. Control 2014, 24, 25-32. [CrossRef] [PubMed]

57. Gunther, R. Are You Often The "Giver" In Your Intimate Relationships? 2019. Available online: https://www.psychologytoday.com/us/blog/rediscovering-love/201902/are-you-often-the-giverin-your-intimate-relationships (accessed on 15 September 2020).

58. Marquez, P.; Zhang, R. China's 2015 Tobacco Tax Adjustment: A Step in The Right Direction. 2016. Available online: https://blogs.worldbank.org/health/china-s-2015-tobacco-tax-adjustment-stepright-direction (accessed on 18 September 2020).

59. Joy, A. Gift giving in Hong Kong and the continuum of social ties. J. Consum. Res. 2001, 28, $239-256$. [CrossRef]

60. Chan, A.; Denton, L.; Tsang, A. The art of gift giving in China. Bus. Horiz. 2003, 46, 47-52. [CrossRef]

61. Moore, M. Death and tobacco taxes. RAND J. Econ. 1999, 27, 415. [CrossRef]

62. Yang, G.; Fan, L.; Samet, J. Smoking among adolescents in China: 1998 survey findings. Int. J. Epidemiol. 2004, 33, 1103-1110. [CrossRef]

63. Huang, L.; Thrasher, J.; Jiang, Y.; Li, Q.; Fong, G.; Quah, A. Incidence and correlates of receiving cigarettes as gifts and selecting preferred brand because it was gifted: Findings from the ITC China Survey. BMC Public Health 2012, 12, 996. [CrossRef]

64. Brandt, A. Inventing conflicts of interest: A history of tobacco industry tactics. Am. J. Public Health 2012, 102, 63-71. [CrossRef]

65. CGTN. Explainer: CPC-Led Multi-Party Cooperation and Political Consultation. 2019. Available online: https: //news.cgtn.com/news/2019-11-21/Graphics-China-s-party-system-explained-LNmPMninCg/index.html (accessed on 16 September 2020). 
66. Zai, J.; Ju, X.; Zhong, G.W. Zhong Guo Kong Zhi Xi Yan Bao Gao Xin Wen Fa Bu Hui (Report on China and Tobacco Control). 2008. Available online: http://www.china.com.cn/fangtan/2008-06/02/content_15583934. htm (accessed on 5 July 2020).

67. Redmon, P.; Chen, L.; Wood, J.; Li, S.; Koplan, J. Challenges for philanthropy and tobacco control in China (1986-2012). Tob. Control 2013, 22, ii4-ii8. [CrossRef]

Publisher's Note: MDPI stays neutral with regard to jurisdictional claims in published maps and institutional affiliations.

(C) 2020 by the authors. Licensee MDPI, Basel, Switzerland. This article is an open access article distributed under the terms and conditions of the Creative Commons Attribution (CC BY) license (http://creativecommons.org/licenses/by/4.0/). 